\title{
Generalization of best proximity points theorem for non-self proximal contractions of first kind
}

\author{
Mohamed ladh Ayari $^{1^{*}}$, Zead Mustafa ${ }^{2}$ and Mohammed Mahmoud Jaradat ${ }^{2}$
}

\author{
"Correspondence: \\ iadh_ayari@yahoo.com \\ ${ }^{1}$ Institute National Des Sciences \\ Appliquée et de Technologie, de \\ Tunis, Carthage University, Tunis, \\ Tunisie \\ Full list of author information is \\ available at the end of the article
}

\begin{abstract}
The primary objective of this paper is the study of the generalization of some results given by Basha (Numer. Funct. Anal. Optim. 31:569-576, 2010). We present a new theorem on the existence and uniqueness of best proximity points for proximal $\beta$-quasi-contractive mappings for non-self-mappings $S: M \rightarrow N$ and $T: N \rightarrow M$. Furthermore, as a consequence, we give a new result on the existence and uniqueness of a common fixed point of two self mappings.
\end{abstract}

MSC: $47 \mathrm{H} 10 ; 54 \mathrm{H} 25$

Keywords: Best proximity points; Proximal $\beta$-quasi-contractive mappings on metric spaces and proximal cyclic contraction

\section{Introduction}

In 1969, Fan in [2] proposed the concept best proximity point result for non-self continuous mappings $T: A \longrightarrow X$ where $A$ is a non-empty compact convex subset of a Hausdorff locally convex topological vector space $X$. He showed that there exists $a$ such that $d(a, T a)=d(T a, A)$. Many extensions of Fan's theorems were established in the literature, such as in work by Reich [3], Sehgal and Singh [4] and Prolla [5].

In 2010, [1], Basha introduce the concept of best proximity point of a non-self mapping. Furthermore he introduced an extension of the Banach contraction principle by a best proximity theorem. Later on, several best proximity points results were derived (see e.g. [6-19]). Best proximity point theorems for non-self set valued mappings have been obtained in [20] by Jleli and Samet, in the context of proximal orbital completeness condition which is weaker than the compactness condition.

The aim of this article is to generalize the results of Basha [21] by introducing proximal $\beta$-quasi-contractive mappings which involve suitable comparison functions. As a consequence of our theorem, we obtain the result of Basha in [21] and an analogous result on proximal quasi-contractions is obtained which was first introduced by Jleli and Samet in $[20]$. (http://creativecommons.org/licenses/by/4.0/), which permits unrestricted use, distribution, and reproduction in any medium, provided you give appropriate credit to the original author(s) and the source, provide a link to the Creative Commons license, and indicate if changes were made. 


\section{Preliminaries and definitions}

Let $(M, N)$ be a pair of non-empty subsets of a metric space $(X, d)$. The following notations will be used throughout this paper: $d(M, N):=\inf \{d(m, n): m \in M, n \in N\} ; d(x, N):=$ $\inf \{d(x, n): n \in N\}$.

Definition 2.1 ([1]) Let $T: M \rightarrow N$ be a non-self-mapping. An element $a_{*} \in M$ is said to be a best proximity point of $T$ if $d\left(a_{*}, T a_{*}\right)=d(M, N)$.

Note that in the case of self-mapping, a best proximal point is the normal fixed point, see $[22,23]$.

Definition 2.2 ([21]) Given non-self-mappings $S: M \rightarrow N$ and $T: N \rightarrow M$. The pair $(S, T)$ is said to form a proximal cyclic contraction if there exists a non-negative number $k<1$ such that

$$
d(u, S a)=d(M, N) \quad \text { and } \quad d(v, T b)=d(M, N) \Longrightarrow d(u, v) \leq k d(a, b)+(1-k) d(M, N)
$$

for all $u, a \in M$ and $v, b \in N$.

Definition 2.3 ([21]) A non-self-mapping $S: M \rightarrow N$ is said to be a proximal contraction of the first kind if there exists a non-negative number $\alpha<1$ such that

$$
d\left(u_{1}, S a_{1}\right)=d(M, N) \quad \text { and } \quad d\left(u_{2}, S a_{2}\right)=d(M, N) \Longrightarrow d\left(u_{1}, u_{2}\right) \leq \alpha d\left(a_{1}, a_{2}\right)
$$

for all $u_{1}, u_{2}, a_{1}, a_{2} \in M$.

Definition 2.4 ([24]) Let $\beta \in(0,+\infty)$. A $\beta$-comparison function is a map $\varphi:[0,+\infty) \rightarrow$ $[0,+\infty)$ satisfying the following properties:

$\left(P_{1}\right) \varphi$ is nondecreasing.

$\left(P_{2}\right) \lim _{n \rightarrow \infty} \varphi_{\beta}^{n}(t)=0$ for all $t>0$, where $\varphi_{\beta}^{n}$ denote the $n$th iteration of $\varphi_{\beta}$ and $\varphi_{\beta}(t)=$ $\varphi(\beta t)$.

$\left(P_{3}\right)$ There exists $s \in(0,+\infty)$ such that $\sum_{n=1}^{\infty} \varphi_{\beta}^{n}(s)<\infty$.

$\left(P_{4}\right)$ (id $\left.-\varphi_{\beta}\right) \circ \varphi_{\beta}(t) \leq \varphi_{\beta} \circ\left(\right.$ id $\left.-\varphi_{\beta}\right)(t)$ for all $t \geq 0$, where id $:[0, \infty) \longrightarrow[0, \infty)$ is the identity function.

Throughout this work, the set of all functions $\varphi$ satisfying $\left(P_{1}\right),\left(P_{2}\right)$ and $\left(P_{3}\right)$ will be denoted by $\Phi_{\beta}$.

Remark 2.1 Let $\alpha, \beta \in(0,+\infty)$. If $\alpha<\beta$, then $\Phi_{\beta} \subset \Phi_{\alpha}$.

We recall the following useful lemma concerning the comparison functions $\Phi_{\beta}$.

Lemma 2.1 ([24]) Let $\beta \in(0,+\infty)$ and $\varphi \in \Phi_{\beta}$. Then

(i) $\varphi_{\beta}$ is nondecreasing;

(ii) $\varphi_{\beta}(t)<t$ for all $t>0$;

(iii) $\sum_{n=1}^{\infty} \varphi_{\beta}^{n}(t)<\infty$ for all $t>0$. 
Definition 2.5 ([20]) A non-self-mapping $T: M \rightarrow N$ is said to be a proximal quasicontraction if there exists a number $q \in[0,1)$ such that

$$
d(u, v) \leq q \max \{d(a, b), d(a, u), d(b, v), d(a, v), d(b, u)\}
$$

whenever $a, b, u, v \in M$ satisfy the condition that $d(u, T a)=d(M, N)$ and $d(v, T b)=$ $d(M, N)$.

\section{Main results and theorems}

Now, we start this section by introducing the following concept.

Definition 3.1 Let $\beta \in(0,+\infty)$. A non-self mapping $T: M \rightarrow N$ is said to be a proximal $\beta$-quasi-contraction if and only if there exist $\varphi \in \Phi_{\beta}$ and positive numbers $\alpha_{0}, \ldots, \alpha_{4}$ such that

$$
d(u, v) \leq \varphi\left(\max \left\{\alpha_{0} d(a, b), \alpha_{1} d(a, u), \alpha_{2} d(b, v), \alpha_{3} d(a, v), \alpha_{4} d(b, u)\right\}\right) .
$$

For all $a, b, u, v \in M$ satisfying, $d(u, T a)=d(M, N)$ and $d(v, T b)=d(M, N)$.

Let $(M, N)$ be a pair of non-empty subsets of a metric space $(X, d)$. The following notations will be used throughout this paper: $M_{0}:=\{u \in M$ : there exists $v \in N$ with $d(u, v)=$ $d(M, N)\} ; N_{0}:=\{v \in N$ : there exists $u \in M$ with $d(u, v)=d(M, N)\}$.

Our main result is giving by the following best proximity point theorems.

Theorem 3.1 Let $(M, N)$ be a pair of non-empty closed subsets of a complete metric space $(X, d)$ such that $M_{0}$ and $N_{0}$ are non-empty. Let $S: M \longrightarrow N$ and $T: N \longrightarrow M$ be two mappings satisfying the following conditions:

$\left(C_{1}\right) S\left(M_{0}\right) \subset N_{0}$ and $T\left(N_{0}\right) \subset M_{0}$;

$\left(C_{2}\right)$ there exist $\beta_{1}, \beta_{2} \geq \max \left\{\alpha_{0}, \alpha_{1}, \alpha_{2}, \alpha_{3}, 2 \alpha_{4}\right\}$ such that $S$ is a proximal $\beta_{1}$-quasicontraction mapping (say, $\psi \in \Phi_{\beta_{1}}$ ) and T is a proximal $\beta_{2}$-quasi-contraction map$\operatorname{ping}\left(\operatorname{say}, \phi \in \Phi_{\beta_{2}}\right)$.

$\left(C_{3}\right)$ The pair $(S, T)$ forms a proximal cyclic contraction.

$\left(C_{4}\right)$ Moreover, one of the following two assertions holds:

(i) $\psi$ and $\phi$ are continuous;

(ii) $\beta_{1}, \beta_{2}>\max \left\{\alpha_{2}, \alpha_{3}\right\}$.

Then $S$ has a unique best proximity point $a_{*} \in M$ and $T$ has a unique best proximity point $b_{*} \in N$. Also these best proximity points satisfy $d\left(a_{*}, b_{*}\right)=d(M, N)$.

Proof Since $M_{0}$ is a non-empty set, $M_{0}$ contains at least one element, say $a_{0} \in M_{0}$. Using the first hypothesis of the theorem, there exists $a_{1} \in M_{0}$ such that $d\left(a_{1}, S a_{0}\right)=d(M, N)$. Again, since $S\left(M_{0}\right) \subset N_{0}$, there exists $a_{2} \in M_{0}$ such that $d\left(a_{2}, S a_{1}\right)=d(M, N)$. Continuing this process in a similar fashion to find $a_{n+1} \in M_{0}$ such that $d\left(a_{n+1}, S a_{n}\right)=d(M, N)$. Since $S$ is a proximal $\beta_{1}$-quasi-contraction mapping for $\psi \in \Phi_{\beta_{1}}$ and since

$$
d\left(a_{n+1}, S a_{n}\right)=d\left(a_{n}, S a_{n-1}\right)=d(M, N),
$$


then by Definition 3.1 we have

$$
\begin{aligned}
d\left(a_{n+1}, a_{n}\right) & \leq \psi\left(\max \left\{\alpha_{0} d\left(a_{n}, a_{n-1}\right), \alpha_{1} d\left(a_{n}, a_{n+1}\right), \alpha_{2} d\left(a_{n}, a_{n-1}\right), \alpha_{4} d\left(a_{n+1}, a_{n-1}\right)\right\}\right) \\
& \leq \psi\left(\max \left\{\begin{array}{c}
\alpha_{0} d\left(a_{n}, a_{n-1}\right), \alpha_{1} d\left(a_{n}, a_{n+1}\right), \alpha_{2} d\left(a_{n}, a_{n-1}\right) \\
\alpha_{4} d\left(a_{n-1}, a_{n}\right)+\alpha_{4} d\left(a_{n}, a_{n+1}\right)
\end{array}\right\}\right) \\
& \leq \psi\left(\max \left\{\begin{array}{c}
\alpha_{0} d\left(a_{n}, a_{n-1}\right), \alpha_{1} d\left(a_{n}, a_{n+1}\right), \alpha_{2} d\left(a_{n}, a_{n-1}\right) \\
2 \alpha_{4} \max \left\{d\left(a_{n-1}, a_{n}\right), d\left(a_{n}, a_{n+1}\right)\right\}
\end{array}\right\}\right) \\
& \leq \psi\left(\beta_{1} \max \left\{d\left(a_{n}, a_{n-1}\right), d\left(a_{n}, a_{n+1}\right)\right\}\right) \\
& =\psi \beta_{1}\left(\max \left\{d\left(a_{n}, a_{n-1}\right), d\left(a_{n}, a_{n+1}\right)\right\}\right) .
\end{aligned}
$$

Now, if $\max \left\{d\left(a_{n}, a_{n-1}\right), d\left(a_{n}, a_{n+1}\right)\right\}=d\left(a_{n}, a_{n+1}\right)$, then by Lemma 2.1 the above inequality becomes

$$
d\left(a_{n+1}, a_{n}\right) \leq \psi_{\beta_{1}}\left(d\left(a_{n+1}, a_{n}\right)\right)<d\left(a_{n+1}, a_{n}\right),
$$

which is a contradiction. Thus, $\max \left\{d\left(a_{n}, a_{n-1}\right), d\left(a_{n}, a_{n+1}\right)\right\}=d\left(a_{n}, a_{n-1}\right)$, then the above inequality (2) becomes

$$
\left.d\left(a_{n+1}, a_{n}\right) \leq \psi_{\beta_{1}}\left(d\left(a_{n-1}, a_{n}\right)\right)\right) .
$$

By applying induction on $n$, the above inequality gives

$$
d\left(a_{n+1}, a_{n}\right) \leq \psi_{\beta_{1}}^{n}\left(d\left(a_{0}, a_{1}\right)\right) \quad \forall n \geq 1
$$

Now, from the axioms of metric and Eq. (3), for positive integers $n<m$, we get

$$
d\left(a_{n}, a_{m}\right) \leq \sum_{k=n}^{m-1} d\left(a_{k}, a_{k+1}\right) \leq \sum_{k=n}^{m-1} \psi_{\beta_{1}}^{k}\left(d\left(a_{1}, a_{0}\right)\right) \leq \sum_{k=1}^{\infty} \psi_{\beta_{1}}^{k}\left(d\left(a_{1}, a_{0}\right)\right)<\infty
$$

Hence, for every $\epsilon>0$ there exists $N>0$ such that

$$
d\left(a_{n}, a_{m}\right) \leq \sum_{k=n}^{m-1} d\left(a_{k}, a_{k+1}\right)<\epsilon \quad \text { for all } m>n>N
$$

Therefore, $d\left(a_{n}, a_{m}\right)<\epsilon$ for all $m>n>N$. That is $\left\{a_{n}\right\}$ is a Cauchy sequence in $M$. But $M$ is a closed subset of the complete metric space $X$, then $\left\{a_{n}\right\}$ converges to some element $a_{*} \in M$.

Since $T\left(N_{0}\right) \subset M_{0}$, by using a similar argument as above, there exists a sequence $\left\{b_{n}\right\} \subset$ $N_{0}$ such that $d\left(b_{n+1}, T b_{n}\right)=d(M, N)$ for each $n$. Since $T$ is a proximal $\beta_{2}$-quasi-contraction mapping (say $\left.\phi \in \Phi_{\beta_{2}}\right)$ and since $d\left(b_{n+1}, T b_{n}\right)=d\left(b_{n}, T b_{n-1}\right)=d(M, N)$, we deduce from Definition 3.1 that

$$
\begin{aligned}
d\left(b_{n+1}, b_{n}\right) & \leq \phi\left(\max \left\{\alpha_{0} d\left(b_{n}, b_{n-1}\right), \alpha_{1} d\left(b_{n}, b_{n+1}\right), \alpha_{2} d\left(b_{n}, b_{n-1}\right), \alpha_{4} d\left(b_{n-1}, b_{n+1}\right)\right\}\right) \\
& \leq \phi\left(\max \left\{\begin{array}{c}
\alpha_{0} d\left(b_{n}, b_{n-1}\right), \alpha_{1} d\left(b_{n}, b_{n+1}\right), \alpha_{2} d\left(b_{n}, b_{n-1}\right), \\
\alpha_{4} d\left(b_{n-1}, b_{n}\right)+\alpha_{4} d\left(b_{n}, b_{n+1}\right)
\end{array}\right\}\right)
\end{aligned}
$$




$$
\begin{aligned}
& \leq \phi\left(\max \left\{\begin{array}{c}
\alpha_{0} d\left(b_{n}, b_{n-1}\right), \alpha_{1} d\left(b_{n}, b_{n+1}\right), \alpha_{2} d\left(b_{n}, b_{n-1}\right), \\
2 \alpha_{4} \max \left\{d\left(b_{n-1}, b_{n}\right), d\left(b_{n}, b_{n+1}\right)\right\}
\end{array}\right\}\right) \\
& \leq \phi\left(\beta_{2} \max \left\{d\left(b_{n}, b_{n-1}\right), d\left(b_{n}, b_{n+1}\right)\right\}\right) \\
& =\phi_{\beta_{2}}\left(\max \left\{d\left(b_{n}, b_{n-1}\right), d\left(b_{n}, b_{n+1}\right)\right\}\right) .
\end{aligned}
$$

Using a similar argument as in the case of $\left\{a_{n}\right\}$, one can show that $\left\{b_{n}\right\}$ is a Cauchy sequence in the closed subset $N$ of the complete space $X$. Thus $\left\{b_{n}\right\}$ converges to $b_{*} \in N$. Now we shall show that $a_{*}$ and $b_{*}$ are best proximal points of $S$ and $T$, respectively. As the pair $(S, T)$ forms a proximal cyclic contraction, it follows that

$$
d\left(a_{n+1}, b_{n+1}\right) \leq k d\left(a_{n}, b_{n}\right)+(1-k) d(M, N) .
$$

Taking the limit as $n \longrightarrow+\infty$, in Eq. (4) we get $d\left(a_{*}, b_{*}\right) \leq k d\left(a_{*}, b_{*}\right)+(1-k) d(M, N)$, and so, $(1-k) d\left(a_{*}, b_{*}\right) \leq(1-k) d(M, N)$. This implies

$$
d\left(a_{*}, a_{*}\right) \leq d(M, N)
$$

Using the fact that $d(M, N) \leq d\left(a_{*}, b_{*}\right)$ and (5), we get $d\left(a_{*}, b_{*}\right)=d(M, N)$. Therefore, we conclude that $a_{*} \in M_{0}$ and $b_{*} \in N_{0}$.

From one hand, since $S\left(M_{0}\right) \subset N_{0}$ and $T\left(N_{0}\right) \subset M_{0}$, there exist $u \in M$ and $v \in N$ such that

$$
d\left(u, S a_{*}\right)=d\left(v, T b_{*}\right)=d(M, N) .
$$

On the other hand, by (1), (6) and using the hypothesis of the theorem that $S$ is a proximal $\beta_{1}$-quasi-contraction mapping, we deduce that

$$
\begin{aligned}
& d\left(a_{n+1}, u\right) \\
& \quad \leq \psi\left(\max \left\{\alpha_{0} d\left(a_{n}, a_{*}\right), \alpha_{1} d\left(a_{n}, a_{n+1}\right), \alpha_{2} d\left(a_{*}, u\right), \alpha_{3} d\left(a_{n}, u\right), \alpha_{4} d\left(a_{*}, a_{n+1}\right)\right\}\right) .
\end{aligned}
$$

For simplicity, we denote

$$
\rho=d\left(a_{*}, u\right)
$$

and

$$
A_{n}=\max \left\{\alpha_{0} d\left(a_{n}, a_{*}\right), \alpha_{1} d\left(a_{n}, a_{n+1}\right), \alpha_{2} d\left(a_{*}, u\right), \alpha_{3} d\left(a_{n}, u\right), \alpha_{4} d\left(a_{*}, a_{n+1}\right)\right\} .
$$

Thus,

$$
\lim _{n \rightarrow+\infty} A_{n}=\max \left\{\alpha_{2}, \alpha_{3}\right\} \rho .
$$

Now, we show by contradiction that $\rho=0$. Suppose that $\rho>0$. First, we consider the case where the assertion (i) of $\left(C_{4}\right)$ is satisfied, that is, $\psi$ is continuous. Then, taking the limit as $n \rightarrow \infty$ in (7) and using (8) and Lemma 2.1, we obtain

$$
\rho \leq \psi\left(\max \left\{\alpha_{2}, \alpha_{3}\right\} \rho\right) \leq \psi\left(\beta_{1} \rho\right)=\psi_{\beta_{1}}(\rho)<\rho,
$$


which is a contradiction. Now, we assume the case where the assertion (ii) of $\left(C_{4}\right)$ is satisfied, that is, $\beta_{1}>\max \left\{\alpha_{2}, \alpha_{3}\right\}$. Then there exist $\epsilon>0$ and integer $N>0$ such that, for all $n>N$, we have

$$
A_{n}<\left(\max \left\{\alpha_{2}, \alpha_{3}\right\}+\epsilon\right) \rho \quad \text { and } \quad \beta_{1}>\max \left\{\alpha_{2}, \alpha_{3}\right\}+\epsilon .
$$

Therefore, the inequality (7) turns into the following inequality:

$$
\begin{aligned}
d\left(a_{n+1}, u\right) & \leq \psi\left(A_{n}\right) \\
& \leq \psi\left(\left(\max \left\{\alpha_{2}, \alpha_{3}\right\}+\epsilon\right) \rho\right)=\psi_{\beta_{1}}\left(\frac{\max \left\{\alpha_{2}, \alpha_{3}\right\}+\epsilon}{\beta_{1}} \rho\right) .
\end{aligned}
$$

Since $\psi \in \Phi_{\beta_{1}}$, by Lemma 2.1 we have

$$
d\left(a_{n+1}, u\right)<\frac{\max \left\{\alpha_{2}, \alpha_{3}\right\}+\epsilon}{\beta_{1}} \rho<\rho .
$$

By letting $n \rightarrow \infty$, the above inequality yields

$$
\rho \leq \frac{\max \left\{\alpha_{2}, \alpha_{3}\right\}+\epsilon}{\beta_{1}} \rho<\rho,
$$

which is a contradiction as well. Thus, in both two cases we get $0=\rho=d\left(a_{*}, u\right)$, which means that $u=a_{*}$ and so from equation (6) we get $d\left(a_{*}, S a_{*}\right)=d(M, N)$. That is $a_{*}$ is a best proximity point for $S$.

Similarly, by using word by word the above argument after replacing $u$ by $v, S$ by $T, \beta_{1}$ by $\beta_{2}$ and $\psi$ by $\phi$, we get that $v=b_{*}$ and hence by (6) $b_{*}$ is a best proximity point for the non-self mapping $T$.

Now, we shall prove that the obtained best proximity points $a_{*}$ of $S$ is unique. Assume to the contrary that there exists $x \in M$ such that $d(x, S x)=d(M, N)$ and $x \neq a_{*}$. Since $S$ is a proximal $\beta_{1}$-quasi-contractive mapping, we obtain

$$
\begin{aligned}
d\left(a_{*}, x\right) & \leq \psi\left(\max \left\{\alpha_{0} d\left(a_{*}, x\right), \alpha_{1} d(x, x), \alpha_{2} d\left(a_{*}, a_{*}\right), \alpha_{3} d\left(a_{*}, x\right), \alpha_{4} d\left(a_{*}, x\right)\right\}\right) \\
& \leq \psi\left(\max \left\{\alpha_{0}, \alpha_{3}, \alpha_{4}\right\} d\left(a_{*}, x\right)\right) \\
& \leq \psi\left(\beta_{1} d\left(a_{*}, x\right)\right)=\psi_{\beta_{1}}\left(d\left(a_{*}, x\right)\right) \\
& <d\left(a_{*}, x\right),
\end{aligned}
$$

which is a contradiction. Similarly, using the same as above and the fact that $T$ is a proximal $\beta_{2}$-quasi-contractive mapping, we see that the best proximity point $b_{*}$ of $T$ is unique.

In Theorem 3.1 by taking $\alpha_{0}=\alpha_{1}=\alpha_{2}=\alpha_{3}=0, \alpha_{4}=1, \beta_{1}=\beta_{2}=1$ and $\psi(t)=\phi(t)=q t$ which is a continuous function and belongs to $\Phi_{1}$, we obtain Corollary 3.3 in [21].

Corollary 3.1 Let $(M, N)$ be a pair of non-empty closed subsets of a complete metric space $(X, d)$ such that $M_{0}$ and $M_{0}$ are non-empty. Let $S: M \longrightarrow N$ and $T: N \longrightarrow M$ be mappings satisfy the following conditions: 
$\left(d_{1}\right) S\left(A_{0}\right) \subset M_{0}$ and $T\left(M_{0}\right) \subset N_{0}$.

$\left(d_{2}\right) S$ and $T$ are proximal quasi-contractions.

$\left(d_{3}\right)$ The pair $(S, T)$ form a proximal cyclic contraction.

Then $S$ has a unique best proximity point $a_{*} \in M$ such that $d\left(a_{*}, S a_{*}\right)=d(M, N)$ and $T$ has a unique best proximity point $b_{*} \in N$ such that $d\left(b_{*}, T b_{*}\right)=d(M, N)$. Also, these best proximity points satisfies $d\left(a_{*}, b_{*}\right)=d(M, N)$.

Proof The result follows immediately from Theorem 3.1 by taking $\alpha_{0}=\alpha_{1}=\alpha_{2}=\alpha_{3}=1$ and $\alpha_{4}=\frac{1}{2}, \beta_{1}=\beta_{2}=1$ and $\psi(t)=\phi(t)=q t$.

The following definition, which was introduced in [24], is needed to derive a fixed point result as a consequence of our main theorem.

Definition 3.2 ([24]) Let $X$ be a non-empty set. A mapping $T: X \rightarrow X$ is called $\beta$-quasicontractive, if there exist $\beta>0$ and $\varphi \in \Phi_{\beta}$ such that

$$
d(T a, T b) \leq \varphi\left(H_{T}(a, b)\right)
$$

where

$$
H_{T}(a, b)=\max \left\{\alpha_{0} d(a, b), \alpha_{1} d(a, T a), \alpha_{2} d(b, T b), \alpha_{3} d(a, T b), \alpha_{4} d(b, T a)\right\},
$$

with $\alpha_{i} \geq 0$ for $i=0,1,2,3,4$.

Corollary 3.2 Let $(X, d)$ be a complete metric space. Let $S, T: X \longrightarrow X$ be two selfmappings satisfying the following conditions:

$\left(E_{1}\right) S$ is $\beta_{1}$-quasi-contractive (say, $\psi \in \Phi_{\beta_{1}}$ ) and $T$ is $\beta_{2}$-quasi-contractive (say, $\phi \in \Phi_{\beta_{2}}$ ).

$\left(E_{2}\right)$ For all $a, b \in X, d(S a, T b) \leq k d(a, b)$ for some $k \in(0,1)$.

$\left(E_{3}\right)$ Moreover, one of the following assertions holds:

(i) $\psi$ and $\phi$ are continuous;

(ii) $\beta_{1}, \beta_{2}>\max \left\{\alpha_{2}, \alpha_{3}\right\}$.

Then $S$ and $T$ have a common unique fixed point.

Proof This result follows from Theorem 3.1 by taking $M=N=X$ and noticing that the hypotheses $\left(E_{1}\right)$ and $\left(E_{2}\right)$ of the corollary coincide with the first, second and the third conditions of Theorem 3.1.

Example 3.1 Let $X=\mathbb{R}$ with the metric $d(x, y)=|x-y|$, then $(X, d)$ is complete metric space. Let $M=[0,1]$ and $N=[2,3]$. Also, let $S: M \longrightarrow N$ and $T: N \longrightarrow M$ be defined by $S(x)=3-x$ and $T(y)=3-y$. Then it is easy to see that $d(M, N)=1, M_{0}=\{1\}$ and $N_{0}=\{2\}$. Thus, $S\left(M_{0}\right)=S(\{1\})=\{2\}=N_{0}$ and $T\left(M_{0}\right)=T(\{2\})=\{1\}=M_{0}$.

Now we show that the pair $(S, T)$ forms a proximal cyclic contraction. $d(u, S a)=$ $d(M, N)=1$ implies that $u=a=1 \in M$ and $d(v, T b=d(M, N)=1$ implies that $v=b=$ $2 \in N$. 
Now, since $d(u, S a)=d(1, S(1))=d(1,2)=1=d(M, N)$ and $d(v, T b)=d(2, T(2))=$ $d(2,1)=1=d(M, N)$. Therefore,

$$
\begin{aligned}
1 & =d(u, v)=d(1,2) \\
& \leq k(d(1,2))+(1-k) d(M, N) \\
& =k+(1-k)=1 .
\end{aligned}
$$

So, $(S, T)$ are proximal cyclic contraction for any $0 \leq k<1$. Now we shall show that $S$ is proximal $\beta_{1}$-quasi-contraction mapping with $\psi(t)=\frac{1}{7} t, \beta_{1}=2$ and $\alpha_{i}=\frac{1}{5}$ for $i=0,1,2,3$ and $\alpha_{4}=\frac{1}{100}$. Note that $\psi(t)=\frac{1}{7} t \in \Phi_{2}$ since $\psi_{\beta_{1}} t=\psi_{2} t=\frac{2}{7} t$. As above the only $a, b, u, v \in$ $M$ such that $d(u, S a)=d(M, N)=1=d(v, S b)$ is $a=b=u=v=1 \in M$. But

$$
\begin{aligned}
0 & =d(u, v)=d(1,1) \\
& \leq \frac{1}{7} \max \left\{\frac{1}{6} d(a, b), \frac{1}{6} d(a, u), \frac{1}{6} d(b, v), \frac{1}{6} d(a, v), \frac{1}{100} d(b, u)\right\} \\
& =\psi\left(\max \left\{\frac{1}{6} d(1,1), \frac{1}{100} d(1,1)\right\}\right) \\
& =\psi(\max \{0,0,0,0,0\}) \\
& =0 .
\end{aligned}
$$

So, $S$ is a proximal $\beta_{1}$-quasi-contraction mapping. We deduce using our Theorem 3.1, that $S$ has a unique best proximity point which is $a_{*}=1$ in this example.

Similarly, by using the same argument as above, we can show that $T$ is proximal $\beta_{2}$ quasi-contraction mapping with $\phi(t)=\frac{1}{8} t, \beta_{2}=3$ and $\alpha_{i}=\frac{1}{6}$ for $i=0,1,2,3$ and $\alpha_{4}=\frac{1}{100}$. Note that $\phi(t)=\frac{1}{8} t \in \Phi_{3}$ since $\phi_{\beta_{2}} t=\phi_{3}(t)=\frac{3}{8} t$. As above the only $a, b, u, v \in N$ such that $d(u, T a)=d(M, N)=1=d(v, T b)$ is $a=b=u=v=2 \in M$. But

$$
\begin{aligned}
0 & =d(u, v)=d((2,2) \\
& \leq \frac{1}{8} \max \left\{\frac{1}{6} d(a, b), \frac{1}{6} d(a, u), \frac{1}{6} d(b, v), \frac{1}{6} d(a, v), \frac{1}{100} d(b, u)\right\} \\
& =\phi\left(\max \left\{\frac{1}{6} d(2,2), \frac{1}{100} d(2,2)\right\}\right) \\
& =\phi(\max \{0,0,0,0,0\}) \\
& =0 .
\end{aligned}
$$

So, $T$ is a proximal $\beta_{2}$-quasi-contraction mapping. We deduce, using Theorem 3.1, that $T$ has a unique best proximity point which is $b_{*}=2$.

Finally, $\psi(t)$ and $\phi(t)$ are continuous mappings as well as $\beta_{1}, \beta_{2}>\max _{0 \leq i \leq 3}\left\{\alpha_{i}\right\}$. Therefore

$$
d\left(a_{*}, b_{*}\right)=d(1,2)=1=d(M, N) .
$$




\section{Conclusion}

Improvements to some best proximity point theorems are proposed. In particular, the result due to Basha [21] for proximal contractions of first kind is generalized. Furthermore, we propose a similar result on existence and uniqueness of best proximity point of proximal quasi-contractions introduced by Jleli and Samet in [20]. This has been achieved by introducing $\beta$-quasi-contractions involving $\beta$-comparison functions introduced in [24].

\section{Acknowledgements}

Not applicable.

Funding

Not applicable.

\section{Abbreviations}

Not applicable.

\section{Availability of data and materials}

Please contact the authors for data requests.

\section{Competing interests}

The authors declare that they have no competing interests.

\section{Authors' contributions}

The authors contributed equally to the preparation of the paper. The authors read and approved the final manuscript.

\section{Author details}

${ }^{1}$ Institute National Des Sciences Appliquée et de Technologie, de Tunis, Carthage University, Tunis, Tunisie. ${ }^{2}$ Department of Mathematics, Satistics and Physics, Qatar University, Doha, Qatar.

\section{Publisher's Note}

Springer Nature remains neutral with regard to jurisdictional claims in published maps and institutional affiliations.

Received: 12 November 2018 Accepted: 30 January 2019 Published online: 25 February 2019

\section{References}

1. Basha, S.S.: Extensions of Banach's contraction principle. Numer. Funct. Anal. Optim. 31, 569-576 (2010)

2. Fan, K.: Extension of two fixed point theorems of F.E Browder. Math. Z. 112, 234-240 (1969)

3. Reich, S.: Approximate selections, best approximations, fixed points and invariant sets. J. Math. Anal. Appl. 62 104-113 (1978)

4. Sehgal, V.M., Singh, S.P.: A generalization to multifunctions of Fan's best approximation theorem. Proc. Am. Math. Soc. 102, 534-537 (1988)

5. Prolla, J.B.: Fixed point theorems for set valued mappings and existence of best approximations. Numer. Funct. Anal. Optim. 5, 449-455 (1983)

6. Basha, S.S.: Best proximity point theorems generalizing the contraction principle. J. Nonlinear Anal. Optim., Theory Appl. 74, 5844-5850 (2011)

7. Basha, S.S.: Best proximity point theorems an exploration of a comon solution to approximation and optimization problems. Appl. Math. Comput. 218, 9773-9780 (2012)

8. Basha, S.S., Sahrazad, N.: Best proximity point theorems for generalized proximal contractions. Fixed Point Theory Appl. 2012, 42 (2012)

9. Sadiq Basha, S., Veeramani, P.: Best approximations and best proximity pairs. Acta Sci. Math. 63, 289-300 (1997)

10. Sadiq Basha, S., Veeramani, P., Pai, D.V.: Best proximity pair theorems. Indian J. Pure Appl. Math. 32, 1237-1246 (2001)

11. Sadiq Basha, S., Veeramani, P.: Best proximity pair theorems for multifunctions with open fibres. J. Approx. Theory 103, 119-129 (2000)

12. Raj, V.S.: A best proximity point theorem for weakly contractive non-self-mappings. Nonlinear Anal. 74, 4804-4808 (2011)

13. Karapinar, E.: Best proximity points of Kannan type-cyclic weak phi-contractions in ordered metric spaces. An. Ştiinţ. Univ. 'Ovidius' Constanța 20, 51-64 (2012)

14. Vetro, C.: Best proximity points: convergence and existence theorems for P-cyclic-mappings. Nonlinear Anal. 73 , 2283-2291 (2010)

15. Samet, B., Vetro, C., Vetro, P.: Fixed points theorems for $\alpha$ - $\psi$-contractive type mappings. Nonlinear Anal. 75, 2154-2165 (2012)

16. Jleli, M., Karapinar, E., Samet, B.: Best proximity points for generalized $\alpha$ - $\psi$ proximal contractives type mapping. J. Appl. Math. 2013, Article ID 534127 (2013)

17. Aydi, H., Felhi, A.: On best proximity points for various $\alpha$-proximal contractions on metric like spaces. J. Nonlinear Sci. Appl. 9(8), 5202-5218 (2016)

18. Aydi, H., Felhia, A., Karapinar, E.: On common best proximity points for generalized $\alpha$ - $\psi$-proximal contractions. J. Nonlinear Sci. Appl. 9(5), 2658-2670 (2016) 
19. Ayari, M.I.: Best proximity point theorems for generalized $\alpha$ - $\beta$-proximal quasi-contractive mappings. Fixed Point Theory Appl. 2017, 16 (2017)

20. Jeli, M., Samet, B.: An optimisation problem involving proximal quasi-contraction mapping. Fixed Point Theory Appl. 2014, 141 (2014)

21. Sadiq, S.: Basha best proximity point theorems generalizing the contraction principle. Nonlinear Anal. 74, 5844-5850 (2011)

22. Shatanawi, W., Mustafa, Z., Tahat, N.: Some coincidence point theorems for nonlinear contraction in ordered metric spaces. Fixed Point Theory Appl. 2011, 68 (2011)

23. Shatanawi, W., Postolache, M., Mustafa, Z., Taha, N.: Some theorems for Boyd-Wong type contractions in ordered metric spaces. Abstr. Appl. Anal. 2012, Article ID 359054 (2012). https://doi.org/10.1155/2012/359054

24. Ayari, M.I., Berzig, M., Kedim, l.: Coincidence and common fixed point results for $\beta$-quasi contractive mappings on metric spaces endowed with binary relation. Math. Sci. 10(3), 105-114 (2016)

Submit your manuscript to a SpringerOpen ${ }^{0}$ journal and benefit from:

- Convenient online submission

- Rigorous peer review

- Open access: articles freely available online

- High visibility within the field

- Retaining the copyright to your article

Submit your next manuscript at $\gg$ springeropen.com 